\title{
Elevated levels of adiponectin associated with major adverse cardiovascular and cerebrovascular events and mortality risk in ischemic stroke
}

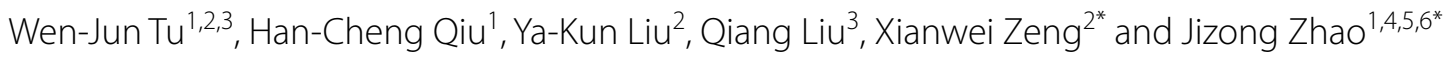

\begin{abstract}
Background: Adiponectin plays role in multiple metabolic pathways. Previous studies in cardiovascular disease evaluated the association between adiponectin and clinical outcomes, yielding conflicting results. The aim of this study was to investigate the association of adiponectin with major adverse cardiovascular and cerebrovascular events (MACCE) and mortality in Chinese patients with first-ever acute ischemic stroke (AIS).
\end{abstract}

Methods: This was a prospective, multicenter cohort study. From September 2009 through October 2015, all patients with AIS from 3 stroke centers in Shandong were included. Serum levels of adiponectin at admission were tested. The prognostic role of adiponectin to predict the MACCE and mortality within 3 years was evaluated by multivariable-adjusted Cox proportional hazards models.

Results: This study included 4274 patients (median age 68 years [interquartile ranges \{|QR\}: 61-76]; 53.2\% men). There were 794 deaths and 899 MACCE events. Higher serum levels of adiponectin on admission were found in patients with MACCE events and nonsurvivors $(P<0.001$ and $P<0.001)$. In multivariable models adjusted for factors that confirmed in the univariate model, elevated serum levels of adiponectin were associated with a higher risk of MACCE (Quartile[Q]4 vs. Q1, Hazard ratio[HR] = 4.95 [95\% confidence interval \{Cl\}: 3.03-7.06]) and mortality (Q4 vs. Q1, $H R=5.63$ [95\% Cl 3.15-7.99]). Adiponectin improved the prognostic value of the National Institutes of Health Stroke Scale (NIHSS) to predict MACCE (combined areas under the curve [AUC], $0.76 ; 95 \% \mathrm{Cl} 0.68-0.88 ; \mathrm{P}=0.001$ ) and mortality $(0.78[0.69-0.91] ; P<0.01)$. Subgroups analysis indicated that the prognostic role of adiponectin was more pronounced in women and patients with high levels of N-terminal-pro B-type natriuretic peptide(NT-pro BNP) $(\mathrm{P}<0.001$ and $\mathrm{P}<0.001$ ).

Conclusions: Elevated serum levels of adiponectin were associated with a higher risk of MACCE and mortality independent of traditional risk factors in ischemic stroke patients.

Keywords: Adiponectin, Ischemic stroke, Mortality, Major adverse cardiovascular and cerebrovascular events, Chinese

\footnotetext{
*Correspondence: wfzwxin@126.com; zhaojz205@163.com

2 Department of Neurosurgery, Qilu Hospital of Shandong University,

No. 107 Wenhua West Road, Jinan 250012, Shandong, People's Republic

of China

${ }^{4}$ China National Clinical Research Center for Neurological Diseases,

Beijing, China

Full list of author information is available at the end of the article
}

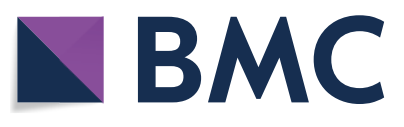

(c) The Author(s) 2020. This article is licensed under a Creative Commons Attribution 4.0 International License, which permits use, sharing, adaptation, distribution and reproduction in any medium or format, as long as you give appropriate credit to the original author(s) and the source, provide a link to the Creative Commons licence, and indicate if changes were made. The images or other third party material in this article are included in the article's Creative Commons licence, unless indicated otherwise in a credit line to the material. If material is not included in the article's Creative Commons licence and your intended use is not permitted by statutory regulation or exceeds the permitted use, you will need to obtain permission directly from the copyright holder. To view a copy of this licence, visit http://creativeco mmons.org/licenses/by/4.0/. The Creative Commons Public Domain Dedication waiver (http://creativecommons.org/publicdomain/ zero/1.0/) applies to the data made available in this article, unless otherwise stated in a credit line to the data. 


\section{Background}

In China, stroke is one of the main causes of death and long-term disability [1]. The GBD 2016 Lifetime Risk of Stroke Collaborators reported that China had the highest estimated lifetime risk of stroke from the age of 25 years onward (39.3\%; 95\% uncertainty interval [UI], 37.5 to 41.1 ) while the global risk was approximately 25\% [2]. Novel and useful biomarkers that can predict stroke prognosis early are of great significance for improving patient prognosis and alleviating medical burden.

Adiponectin, first identified in 1995, is a 244-amino acid collagen-like protein [3]. It is secreted by adipocytes and plays role in anti-inflammatory and insulin-sensitizing properties [3]. The dysregulation of adiponectin has been implicated in obesity, metabolic syndrome, type 2 diabetes, hypertension, and cardiovascular disease $[4,5]$. Adiponectin signaling plays role in the brain functions (fatty acid oxidation, energy homeostasis, hippocampal neurogenesis, and synaptic plasticity) through its receptors, AdipoR1 and AdipoR2 $[6,7]$.

Previous vitro studies illustrated that adiponectin could be seen as a cardioprotective molecule [8, 9]. $\mathrm{Hu}$ et al. [10] showed that higher levels of adiponectin related to decreased risk of cardiovascular diseases and mortality in US women. On the contrary, positive relationships between adiponectin and mortality in many clinical conditions, such as kidney disease [11], heart failure (HF) [12], cardiovascular disease (CVD) [13] and general elderly cohorts [14] had been declared. This contradictory phenomenon is so-called adiponectin "paradox" [15]. The biology underlying this paradox is unknown.

The adiponectin "paradox" also presents among patients with stroke. One study showed that elevated serum adiponectin levels were associated with a high risk of ischemic stroke [16], while other studies reported that decreased adiponectin related to poststroke depression [17] and cerebrovascular disease [18]. Furthermore, some studies reported that adiponectin serum levels were not associated with risk of stroke among different populations [19, 20]. Similarly, one study showed that low adiponectin plasma levels were independently associated with a high risk of 5-year mortality after first-ever AIS [21], while another study indicated that elevated adiponectin levels related to a high risk of recurrence events and mortality in patients with coronary heart disease [22]. The pathophysiological and prognostic role of adiponectin in CVD and cerebrovascular disease is still obscure [23].

The aim of this study was to investigate the association of adiponectin with major adverse cardiovascular and cerebrovascular events (MACCE) and mortality in Chinese patients with first-ever acute ischemic stroke (AIS).

\section{Patients and methods \\ Patient population}

This was a prospective, multicenter cohort study. From September 2009 through October 2015, all patients with first-ever AIS with symptom onset within $24 \mathrm{~h}$ from 3 stroke centers in Shandong were included. Diagnosis of AIS was confirmed according to the World Health Organization ICD-9 criteria and computed tomography (CT) and/or magnetic resonance imaging (MRI) were used to verification diagnosis [24]. Exclusion criteria were as following: (1) malignant tumor and/or metabolic syndrome(not included diabetes mellitus); (2) renal and/ or liver insufficiency (renal insufficiency was confirmed according to creatinine level [men with a creatinine level $\geq 1.5 \mathrm{mg} / \mathrm{dl}$ and women $\geq 1.3 \mathrm{mg} / \mathrm{dl}]$ ); (3) surgical operation in the past 3 months; (4) acute and/or chronic medical illness (sepsis, pneumonia, infection and neurological illness other than stroke); and (5) no informed consent, lost blood specimens and lost flow-up.

\section{Clinical variables and neuroimaging}

At admission, demographical and clinical data were collected: age, sex, body mass index (BMI, defined as the body weight $[\mathrm{kg}]$ divided by the square of the body height $\left[\mathrm{m}^{2}\right]$ ) and vascular risk factors (hypertension, diabetes mellitus, atrial fibrillation, hyperlipoproteinemia, coronary heart disease and smoking habit). The information about previous CVD events and family history for stroke were also collected. Pre-stroke treatment (Aspirin, Clopidogrel, Anticoagulation, Statins and Renin-angiotensin system blockers) and acute treatment information were obtained. Stroke severity on admission was evaluated using the National Institutes of Health Stroke Scale (NIHSS) [25]. Stroke subtype and syndrome were assessed by TOAST (Trial of Org 10172 in Acute Stroke Treatment) criteria and the Oxfordshire Community Stroke Project, respectively [26]. MRI was performed in some patients and diffusion-weighted imaging (DWI) lesion volumes was calculated [26].

\section{End points and follow-up}

For follow-up, we used structured telephone interviews performed by 12 trained medical students, blinded to blood levels. In our study, the primary end point in stroke patients was incident MACCE (a composite of CVD death, nonfatal myocardial infarction, nonfatal stroke, or coronary revascularization by percutaneous coronary intervention or coronary artery bypass grafting) [27] of 
stroke patients after 3 years from baseline. Secondary end point was all-cause mortality within a 3-year follow-up.

\section{Blood samples test}

For all patients, fasting serum samples were collected within $24 \mathrm{~h}$ of admission and stored at $-80{ }^{\circ} \mathrm{C}$. The serum concentration of adiponectin was tested by an enzyme-linked immunosorbent assay (ELISA) method (No, ab99968; Abcam Trading [Shanghai] Company Ltd. Shanghai, China) with a detection limit of $0.25 \mu \mathrm{g} / \mathrm{mL}$. The intra-assay and inter-assay coefficients of variation (CV) were all less than $10.0 \%$. Other biomarkers including glucose, C-reactive protein (CRP), copeptin and $\mathrm{N}$-terminal of the prohormone B-type natriuretic peptide (NT-proBNP) were also tested [24]. In addition, the estimated glomerular filtration rate (eGFR) of these subjects was calculated according to the creatinine levels using the Chronic Kidney Disease Epidemiology Collaboration (CKD-EPI) formula [28]. Two hundred age and gendermatched healthy volunteers from our medical center were chosen to assess the normal concentration range of serum adiponectin. Volunteers with any sub-clinical stroke features would be excluded. The fasting serum samples of those volunteers were collected and serum levels of adiponectin were tested.

\section{Statistical analysis}

In this study, categorical variables were presented as number (percentages, \%) and continuous variables were presented as medians (interquartile ranges, IQRs). Continuous variables were tested for normality by ShapiroWilk tests. Mann-Whitney U test (continuous variables) or Chi square test (categorical variables) was used for comparison between groups. Spearman's rank was used to assess the bivariate correlations.

The association between adiponectin and two endpoints (MACCE and mortality) was evaluated by the Cox proportional hazards models and the results were reported as hazard ratios (HR) and 95\% confidence interval (CI). Multivariable models were adjusted for those significantly factors which had been confirmed in the univariate model.

The accuracy of serum adiponectin in predicting wo endpoints (MACCE and mortality) was analyzed by receiver operating characteristic (ROC) curves and the results were reported as area under the curve (AUC) and 95\%CI. The cut-off of adiponectin value was calculated. The clinical value of adding adiponectin to the existing risk factors for predicting the two endpoints was further calculated by the net reclassification improvement (NRI) index. In addition, to investigate the ability of adiponectin for wo endpoints (MACCE and mortality) prediction, we used Kaplan-Meier survival curves and stratified patients by adiponectin quartiles and compared with the log-rank test.

Lastly, we performed subgroup analyses and stratified patients by age ( $<60$ vs. $\geq 60$ years), sex (men vs. women), BMI ( $<27 \mathrm{vs.} \geq 27 \mathrm{~kg} / \mathrm{m}^{2}$ ), diabetes status (yes vs. no), $\operatorname{eFGR}\left(<60\right.$ vs. $\left.\geq 60 \mathrm{~mL} / \mathrm{min} / 1.73 \mathrm{~m}^{2}\right), \operatorname{CRP}(<5$ vs. $\geq 5 \mathrm{mg} / \mathrm{l}$ ), copeptin (<median vs. $\geq$ median)and NTProBNP $(<$ median vs. $\geq$ median $)$. We used the following statistical software: SPSS Statistics (version 24.0; IBM Corp., Armonk, NY, USA), the ROCR package (version 1.0-2; http://cran.r-project.org/) and GraphPad Prism (version 5.0; GraphPad Software, La Jolla, CA, USA). A P value $<0.05$ (2-sided) indicated significance.

\section{Ethics}

The design and proposal were reviewed and approved by Ethics Committee of the Weifang Medical University Affiliated Hospital according to the principles of the Declaration of Helsinki (trial registration no. ChiCTRROC-17013501). Written informed consents were collected from patients or their relatives (patients unable to communicate) before they participated in the study.

\section{Results}

\section{Patient characteristics}

Finally, as shown in the Fig. 1, 4274 patients with AIS were included. The baseline characteristics [age $(\mathrm{P}=0.62)$, gender $(\mathrm{P}=0.87)$, and $\mathrm{BMI}(\mathrm{P}=0.81)]$ of those patients were similar to the overall cohort. The median follow-up period was 3.0 years (mean: 3.03 years). In addition, $53.2 \%$ of those patients were male and the median age of was 68 years (IQR:61-76). The median serum level of adiponectin at admission was $7.1 \mu \mathrm{g} / \mathrm{mL}$ (IQR:4.8-9.8), which was higher than in those healthy controls $(6.0[4.1-7.2] \mu \mathrm{g} / \mathrm{mL}), P<0.001$. More information had been presented in the Table 1.

\section{Baseline adiponectin and MACCE}

During the 3-year follow-up period, 899 patients (21.0\%; 95\%CI $19.8 \%-22.3 \%)$ were defined as MACCE, and the adiponectin serum levels in those patients were significantly higher than those without MACCE (9.8[IQR: 6.911.8] $\mu \mathrm{g} / \mathrm{mL}$ vs. $6.6[4.5-8.9] \mu \mathrm{g} / \mathrm{mL} ; P<0.001)$, Fig. $2 \mathrm{a}$. Elevated serum levels of adiponectin (continuous variable) related to a high risk of MACCE. Per one-unit ( $\mu \mathrm{g} /$ $\mathrm{mL}$ ) increase, the risk of MACCE increased by $20 \%$ (HR, 1.20; 95\%CI 1.1-8-1.23), Table 2. The risk of MACCE was distributed across adiponectin quartiles, from $8.1 \%$ (first quartile, Q1) to $40.5 \%$ (fourth quartile, Q4). Patients in the Q4 had a 6.73-fold higher risk of MACCE (HR, 7.73; 95\%CI 6.02-9.92) as compared with patients in Q1. Similarly, patients in the 2nd and 3rd quartiles of adiponectin 


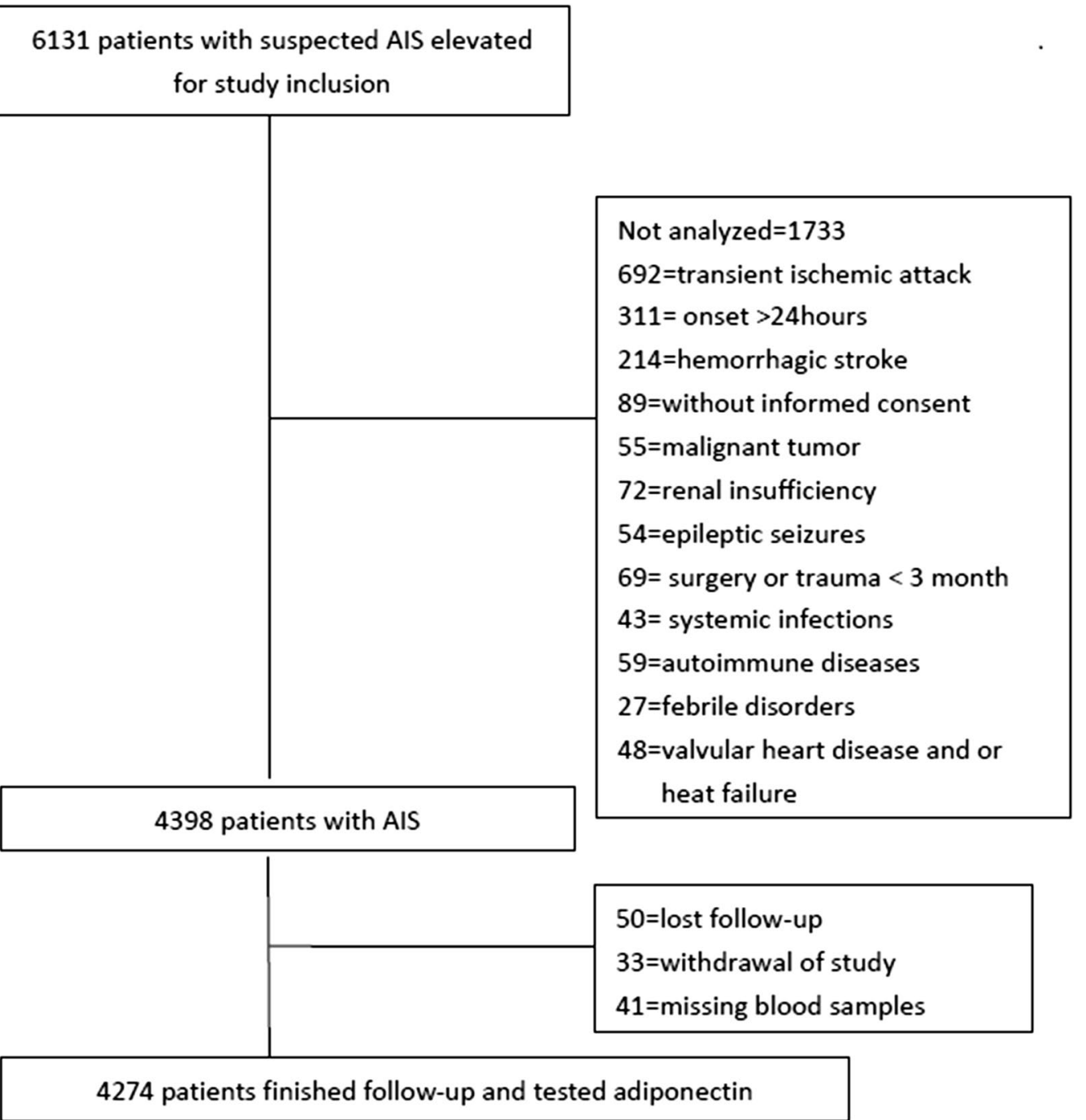

Fig. 1 Study profile/flow sheet of the study

also related to high risk of MACCE and the risk increased by $94 \%$ (HR, 1.94;95\%CI $1.47-2.56)$ and $214 \%$ (3.14; 2.42-4.08), respectively.

As showed in the Table 2, univariate Cox regression analysis for MACCE were performed. We further evaluated potentially factors: sex, BMI, NTpro-BNP, and CRP. Women patients had higher levels of adiponectin when compared with men patients (7.9[IQR: 5.8-10.7] $\mu \mathrm{g} /$ $\mathrm{mL}$ vs. 6.6[4.2-9.0] $\mu \mathrm{g} / \mathrm{mL} ; \mathrm{p}<0.001)$. Adiponectin was inversely correlated to $\mathrm{BMI}(\mathrm{r}=0.198, \mathrm{P}<0.001)$, positively to NT-pro-BNP $(\mathrm{r}=0.275, \mathrm{P}<0.001)$ and CRP $(\mathrm{r}=0.216, \mathrm{P}<0.001)$. Adjustments for age, sex (female vs. male), obese (yes vs. no), diabetes mellitus (yes vs. no), atrial fibrillation (yes vs. no), previous CVD events (yes vs. no), NHISS, stroke syndrome (TACS vs. other), stroke subtype (Cardioembolic vs. other), acute treatment (no vs. yes), serum glucose, CRP, eGFR, copeptin and NT-ProBNP, per one-unit $(\mu \mathrm{g} / \mathrm{mL})$ increase in adiponectin, the risk of MACCE increased by $13 \%$ (HR, 1.13; 95\%CI 1.06-1.19), Table 3. In the analysis of multivariable models, the Q2, Q3, and Q4 of adiponectin levels were compared against Q1 (Fig. 2b). As shown in the Fig. 2b, adiponectin levels in Q2, Q3, and Q4 related to MACCE and the risk was increased by $43 \%$ (HR 1.43 , 95\% CI 1.11-2.08), $133 \%$ (2.33, 1.55-3.08) and 395\% (4.95, 3.03-7.06), respectively as compared with patients in Q1. The independence of correlation between adiponectin and MACCE was tested by the likelihood ratio test $(\mathrm{P}<0.001)$. In addition, age, BMI, diabetes mellitus, previous CVD events, acute treatment, CRP, copeptin, 
Table 1 Baseline characteristics of stroke patients ${ }^{a}$

\begin{tabular}{|c|c|}
\hline Baseline characteristics & All \\
\hline N & 4274 \\
\hline Age, years & $68(61-76)$ \\
\hline Male gender & $2274(53.2)$ \\
\hline BMl, kg/m2 & $26.2(24.4-28.6)$ \\
\hline \multicolumn{2}{|l|}{ Vascular risk factors } \\
\hline Hypertension & $1848(43.2)$ \\
\hline Diabetes mellitus & $1011(23.7)$ \\
\hline Hypercholesterolemia & $881(20.6)$ \\
\hline Atrial fibrillation & $842(19.7)$ \\
\hline Coronary heart disease & $1103(25.8)$ \\
\hline Current smoking & $762(17.8)$ \\
\hline Previous CVD events & $791(18.5)$ \\
\hline Family history for stroke & $693(16.2)$ \\
\hline NIHSS score at admission & $7(4-13)$ \\
\hline DWl lesion size $(\mathrm{N}=2812), \mathrm{ml}$ & $21.3(7.2-41.8)$ \\
\hline Time to blood collection, hours & $5.2(3.2-11.1)$ \\
\hline \multicolumn{2}{|l|}{ Stroke syndrome } \\
\hline TACS & $966(22.6)$ \\
\hline PACS & $1650(38.6)$ \\
\hline LACS & $752(17.6)$ \\
\hline POCS & $906(21.2)$ \\
\hline \multicolumn{2}{|l|}{ TOAST subtype } \\
\hline Large-vessel disease & $756(17.7)$ \\
\hline Small-artery disease & $700(16.4)$ \\
\hline Cardioembolic & $1041(24.4)$ \\
\hline Multiple causes & $758(17.7)$ \\
\hline Other known & $558(13.1)$ \\
\hline Undetermined & $461(10.8)$ \\
\hline \multicolumn{2}{|l|}{ Laboratory findings, serum levels } \\
\hline Glucose, mmol/l & $6.3(5.5-7.5)$ \\
\hline Creatinine, $\mathrm{mmol} / \mathrm{l}$ & $81.1(69.0-95.0)$ \\
\hline eGFR, e mL/min/1.73 m² & $75.0(60.8-91.9)$ \\
\hline CRP, mg/l & $3.9(2.4-9.5)$ \\
\hline Copepin, pmol// & $20.1(14.9-28.3)$ \\
\hline NT-ProBNP, pg/ml & $1111(266-3722)$ \\
\hline Adiponectin, $\mu \mathrm{g} / \mathrm{mL}$ & $7.1(4.8-9.8)$ \\
\hline \multicolumn{2}{|l|}{ Therapies before admission } \\
\hline Aspirin & $900(21.1)$ \\
\hline Clopidogrel & $464(10.9)$ \\
\hline Anticoagulation & $855(20.0)$ \\
\hline Statins & $1302(30.5)$ \\
\hline Renin-angiotensin system blockers & $1541(36.1)$ \\
\hline \multicolumn{2}{|l|}{ Acute treatment } \\
\hline Endovascular/surgical revascularization & $312(7.3)$ \\
\hline
\end{tabular}

$B M I$ body mass index, NIHSS National Institutes of Health Stroke Scale, TACS total anterior circulation syndrome, PACS partial anterior circulation syndrome, LACS lacunar syndrome, POCS posterior circulation syndrome, GFR glomerular filtration rate, CRP C-reactive protein, NT-proBNP N-terminal fragment of precursor of B-type natriuretic peptide, CVD cardiovascular disease

a The results were presented as $n$ (percentages) for categorical variables and as medians (interquartile ranges,IQRs) for continuous variables
BNP and the NIHSS score were significant MACCE predictors, unlike others factors (Table 3).

The ROC curve was applied for choosing the cut-off value of adiponectin in predicting MACCE, Fig. 2c. An optimal value of $9.2 \mu \mathrm{g} / \mathrm{mL}$ produced a sensitivity of $55.3 \%$ and a specificity of $76.7 \%$, with AUC (95\% CI) of 0.71 (0.61-0.82), which showed a significantly greater discriminatory ability as compared with other factors (Table 4). There was a positive association with MACCE when adiponectin levels above cut-off point (HR 3.21, 95\% CI 2.36-4.14; $\mathrm{P}<0.001)$.

In a combined model, the AUC of the NIHSS score could be increased with adiponectin $(0.76 ; 95 \%$ CI $0.68-0.88, \mathrm{P}=0.001)$. As shown in the Table 4, the combined model IV (with adiponectin) improved the model III (without adiponectin) (AUC, 0.81[0.69-0.93] vs. $0.77[0.68-0.86] ; \mathrm{P}=0.013$ ). The average AUC (standard error) for combined IV and III were $0.81(0.025)$ and 0.77 (0.036), corresponding to a difference of 0.04 (0.011). The inclusion of adiponectin as a variable showed a significant improvement in risk estimation over traditional variables for MACCE at 3 years as monitored by NRI (0.32; 95\%CI [0.25-0.41]; P <0.001). The Kaplan-Meier estimates of MACCE stratified by baseline adiponectin quartiles was showed in Fig. 2d. Patients in the lowest quartile (adiponectin $<4.8 \mu \mathrm{g} / \mathrm{mL}$ ) had a minimal risk for MACCE, in contrast with patients with adiponectin levels in the 2nd, 3rd and 4th quartiles (adiponectin between 4.8 and $7.1 \mu \mathrm{g} / \mathrm{mL}, 7.1$ and $9.8 \mu \mathrm{g} / \mathrm{mL}$ and $>9.8 \mu \mathrm{g} / \mathrm{mL}$, respectively) $(\mathrm{P}<0.001$, log-rank test $)$.

\section{Baseline adiponectin and all-cause mortality}

Finally, 794 patients (18.6\%; 95\%CI 17.5\%-19.9\%) died, and serum adiponectin levels in those patients were higher than in those survivals (9.9[IQR: $7.3-12.3] \mu \mathrm{g} / \mathrm{mL}$ vs. 6.6[4.5-9.0] $\mu \mathrm{g} / \mathrm{mL} ; \mathrm{P}<0.001)$, Fig. 3a. Elevated serum adiponectin related to a high risk of mortality. Per oneunit $(\mu \mathrm{g} / \mathrm{mL})$ increase in adiponectin, the risk of mortality increased by $23 \%$ (HR, 1.23; 95\%CI 1.20-1.27), Table 2 . The risk of mortality was distributed across adiponectin quartiles, from 6.7\% (first quartile, Q1) to 36.3\% (fourth quartile, Q4). Patients in the 2nd, 3rd and highest quartiles of adiponectin had higher risk of mortality and the risk was increased by $91 \%$ (HR, 1.91;95\%CI 1.30-2.59), $242 \%(3.42 ; 2.57-4.56)$ and $813 \%(9.13 ; 6.95-11.99)$, respectively as compared with patients in the Q1.

As showed in the Table 2, univariate Cox regression analysis for mortality were performed. Adjustments for age, obese (yes vs. no), previous CVD events (yes vs. no), NHISS, stroke syndrome (TACS vs. other), stroke subtype (Cardioembolic vs. other), acute treatment (no vs. yes), serum levels of glucose, CRP, eGFR, copeptin 


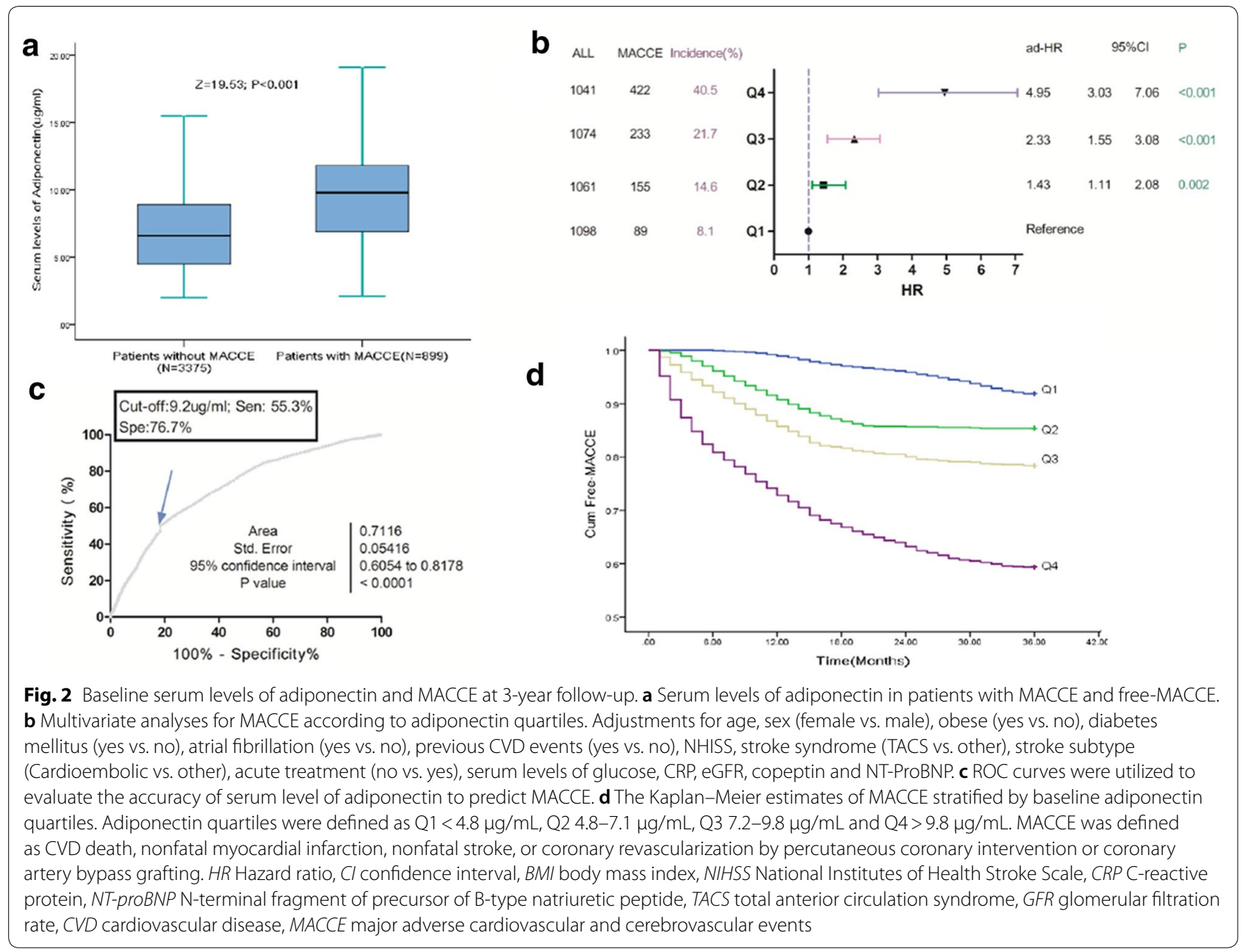

and NT-ProBNP, per one-unit $(\mu \mathrm{g} / \mathrm{mL})$ increase in adiponectin, the risk of mortality increased by $17 \%$ (HR, 1.17; $95 \%$ CI 1.11-1.24), Table 3 . In the analysis of multivariable models, the $2 \mathrm{nd}$, 3rd and highest adiponectin quartiles levels were compared against lowest quartile (Fig. 3b). As shown in the Fig. 3b, adiponectin levels in Q2, Q3, and Q4 were correlated with mortality and the risk was increased by $39 \%$ (HR 1.39, 95\% CI 1.08-1.26), $140 \%(2.40,1.53-3.15)$ and $463 \%$ (5.63, 3.15-7.99), respectively. The independence of correlation between adiponectin and mortality was tested by the likelihood ratio test $(\mathrm{P}<0.001)$. In addition, age, $\mathrm{BMI}$, acute treatment, CRP, copeptin, BNP and the NIHSS score were significant mortality predictors, unlike others factors (Table 3).

The ROC curve was applied for choosing the cut-off value of adiponectin in predicting MACCE, Fig. 3c. An optimal value of $9.0 \mu \mathrm{g} / \mathrm{mL}$ produced a sensitivity of $60.6 \%$ and a specificity of $74.9 \%$, with AUC (95\% CI) of 0.73 (0.58-0.89), which showed a significantly greater discriminatory ability as compared with other factors (Table 4). There was a positive association with total mortality when adiponectin levels above cut-off point (HR 4.45, 95\% CI 3.28-5.81; P<0.001).

In a combined model, the AUC of the NIHSS score could be increased with adiponectin (0.78; 95\% CI 0.69-0.91, $\mathrm{P}<0.001)$. As shown in the Table 4 , the combined model IV (with adiponectin) improved the combined model III (without adiponectin) (AUC [95\%CI], 0.84[0.72-0.96] vs. $0.80[0.69-0.92] ; P=0.005$ ). The average AUC (standard error) for combined IV and III were $0.84(0.015)$ and 0.80 (0.026), corresponding to a difference of 0.04 (0.011). The inclusion of adiponectin as a variable showed a significant improvement in risk estimation over traditional variables for mortality at 3 years as monitored by NRI $(0.35$; $95 \%$ CI $0.27-$ 0.45; $\mathrm{P}<0.001)$. The Kaplan-Meier estimates of mortality stratified by baseline adiponectin quartiles was showed in Fig. 3d. Again, patients in the lowest quartile (adiponectin $<4.8 \mu \mathrm{g} / \mathrm{mL}$ ) had a minimal risk for mortality, in contrast with patients with adiponectin levels in the 2 nd, 3rd and 4th 
Table 2 Univariate Cox regression analysis for MACCE and Mortality in stroke patients during 3-year follow-up

\begin{tabular}{|c|c|c|c|c|c|c|}
\hline \multirow[t]{2}{*}{ Parameter } & \multicolumn{3}{|c|}{ MACCE $^{a}$} & \multicolumn{3}{|c|}{ Mortality } \\
\hline & HR & $95 \% \mathrm{Cl}$ & $P$ & HR & $95 \% \mathrm{Cl}$ & $P$ \\
\hline Age (increase per unit) & 1.08 & $1.02-1.16$ & 0.005 & 1.13 & $1.06-1.19$ & $<0.001$ \\
\hline Sex (female vs. male) & 1.65 & $1.19-2.55$ & 0.015 & 1.33 & $0.85-2.18$ & 0.39 \\
\hline $\mathrm{BMI}(\geq 30 \mathrm{vs} .<30$ kg/m²) & 1.21 & $1.07-1.37$ & 0.009 & 1.28 & $1.08-1.43$ & 0.005 \\
\hline \multicolumn{7}{|l|}{ Vascular risk factors (yes vs. no) } \\
\hline Hypertension & 1.63 & $1.05-3.01$ & 0.29 & 1.75 & $0.93-3.15$ & 0.21 \\
\hline Diabetes mellitus & 1.25 & $1.07-1.46$ & 0.012 & 1.09 & $0.85-2.41$ & 0.59 \\
\hline Atrial fibrillation & 1.81 & $1.28-2.74$ & 0.007 & 3.01 & $0.95-5.33$ & 0.17 \\
\hline Coronary heart disease & 1.48 & $0.90-2.77$ & 0.42 & 2.11 & $1.02-3.43$ & 0.07 \\
\hline Hypercholesterolemia & 0.85 & $0.73-1.54$ & 0.27 & 0.93 & $0.82-1.42$ & 0.19 \\
\hline Current smoking & 1.43 & $0.89-2.29$ & 0.39 & 1.76 & $0.73-3.88$ & 0.53 \\
\hline Previous CVD events & 1.25 & $1.09-1.49$ & 0.009 & 1.32 & $1.02-1.74$ & 0.011 \\
\hline Family history for stroke & 0.89 & $0.69-1.59$ & 0.59 & 0.93 & $0.73-2.05$ & 0.52 \\
\hline Infarct volume (increase per unit), $n=2810$ & 1.25 & $1.12-1.39$ & 0.007 & 1.31 & $1.10-1.44$ & 0.006 \\
\hline NIHSS (increase per unit) & 1.17 & $1.12-1.23$ & $<0.001$ & 1.19 & $1.14-1.27$ & $<0.001$ \\
\hline Time to blood collection & 1.59 & $0.83-2.74$ & 0.45 & 1.79 & $0.93-3.15$ & 0.63 \\
\hline \multicolumn{7}{|l|}{ Stroke syndrome } \\
\hline TACS & 3.75 & $1.85-6.65$ & 0.001 & 4.72 & $2.03-7.59$ & $<0.001$ \\
\hline PACS & 1.55 & $0.75-2.65$ & 0.61 & 0.85 & $0.41-1.66$ & 0.61 \\
\hline LACS & 0.70 & $0.44-1.63$ & 0.39 & 0.59 & $0.36-1.32$ & 0.13 \\
\hline POCS & 0.43 & $0.25-0.65$ & 0.015 & 0.48 & $0.23-1.03$ & 0.20 \\
\hline \multicolumn{7}{|l|}{ TOAST subtype } \\
\hline Large-vessel disease & 0.95 & $0.55-1.98$ & 0.43 & 0.55 & $0.32-1.32$ & 0.26 \\
\hline Small-artery disease & 0.76 & $0.47-1.75$ & 0.38 & 0.69 & $0.39-1.54$ & 0.33 \\
\hline Cardioembolic & 1.19 & $1.02-1.62$ & 0.032 & 1.55 & $1.08-2.03$ & 0.016 \\
\hline Multiple causes & 0.93 & $0.66-1.76$ & 0.64 & 0.82 & $0.45-2.04$ & 0.87 \\
\hline Other known & 1.51 & $0.99-2.14$ & 0.09 & 1.42 & $0.87-2.01$ & 0.18 \\
\hline Undetermined & 0.65 & $0.21-1.61$ & 0.28 & 0.72 & $0.33-1.82$ & 0.31 \\
\hline \multicolumn{7}{|l|}{ Therapies before admission } \\
\hline Aspirin & 0.95 & $0.46-2.38$ & 0.85 & 0.93 & $0.76-2.87$ & 0.93 \\
\hline Clopidogrel & 1.74 & $0.77-3.92$ & 0.68 & 1.55 & $0.80-3.05$ & 0.51 \\
\hline Anticoagulation & 0.83 & $0.45-1.79$ & 0.07 & 0.76 & $0.54-1.56$ & 0.15 \\
\hline Statins & 1.25 & $0.67-1.97$ & 0.56 & 1.22 & $0.98-1.65$ & 0.09 \\
\hline Renin-angiotensin system blockers & 0.93 & $0.80-1.48$ & 0.23 & 0.90 & $0.69-1.65$ & 0.18 \\
\hline Acute treatment (no vs. yes) & 3.78 & $2.04-5.54$ & $<0.001$ & 4.48 & $3.01-6.12$ & $<0.001$ \\
\hline \multicolumn{7}{|l|}{ Blood biomarkers } \\
\hline Glucose (increase per unit) & 1.09 & $1.01-1.27$ & 0.031 & 1.12 & $1.03-1.22$ & 0.003 \\
\hline Creatinine (increase per unit) & 1.02 & $0.90-1.48$ & 0.27 & 1.05 & $0.85-1.53$ & 0.31 \\
\hline eGFR (increase per unit) & 1.05 & $1.01-1.12$ & 0.011 & 1.09 & $1.03-1.24$ & 0.028 \\
\hline CRP (increase per unit) & 1.05 & $1.01-1.10$ & 0.006 & 1.09 & $1.02-1.19$ & 0.013 \\
\hline Copepin (Q4 vs. Q1-3) & 3.74 & $2.55-5.39$ & $<0.001$ & 4.83 & $3.04-7.16$ & $<0.001$ \\
\hline NT-ProBNP (Q4 vs. Q1-3) & 3.15 & $2.12-4.55$ & $<0.001$ & 3.98 & $2.36-5.47$ & $<0.001$ \\
\hline Adiponectin (increase per unit) & 1.20 & $1.18-1.23$ & $<0.001$ & 1.23 & $1.20-1.27$ & $<0.001$ \\
\hline
\end{tabular}

HR Hazard ratio, Cl confidence interval, BMI body mass index, NIHSS National Institutes of Health Stroke Scale, CRP C-reactive protein, NT-proBNP N-terminal fragment of precursor of B-type natriuretic peptide, TACS total anterior circulation syndrome, GFR glomerular filtration rate, CVD cardiovascular disease, MACCE major adverse cardiovascular and cerebrovascular events

a MACCE was defined as CVD death, nonfatal myocardial infarction, nonfatal stroke, or coronary revascularization by percutaneous coronary intervention or coronary artery bypass grafting 
Table 3 Multivariate Cox analysis of MACCE and mortality in stroke patients during 3-year follow-up

\begin{tabular}{|c|c|c|c|c|}
\hline \multirow[t]{2}{*}{ Variable } & \multicolumn{2}{|l|}{ MACCE $^{\mathrm{a}}$} & \multicolumn{2}{|l|}{ Mortality ${ }^{\mathbf{b}}$} \\
\hline & $\mathrm{HR}(95 \% \mathrm{Cl})$ & $\mathbf{P}$ & $\mathrm{HR}(95 \% \mathrm{Cl})$ & $\mathbf{P}$ \\
\hline Age (increase per unit) & $1.08(1.01-1.16)$ & 0.009 & $1.11(1.04-1.19)$ & 0.006 \\
\hline Sex (female vs. male) & $1.43(0.90-2.15)$ & 0.16 & - & \\
\hline $\mathrm{BMI}(\geq 30 \mathrm{vs.}<30$ kg/m2) & $1.16(1.04-1.26)$ & 0.018 & $1.18(1.03-1.29)$ & 0.016 \\
\hline Diabetes mellitus (yes vs. no) & $1.11(1.02-1.32)$ & 0.042 & - & \\
\hline Atrial fibrillation (yes vs. no) & $1.48(0.92-2.67)$ & 0.063 & - & \\
\hline Previous CVD events (yes vs. no) & $1.12(1.02-1.25)$ & 0.016 & $1.15(0.99-1.38)$ & 0.15 \\
\hline NIHSS (increase per unit) & $1.14(1.07-1.23)$ & $<0.001$ & $1.16(1.09-1.24)$ & $<0.001$ \\
\hline Stroke syndrome (TACS vs. other) & $2.25(0.75-4.32)$ & 0.38 & $2.56(0.68-4.76)$ & 0.43 \\
\hline Stroke subtype (Cardioembolic vs. other) & $1.07(0.86-2.14)$ & 0.26 & $1.14(0.97-1.89)$ & 0.18 \\
\hline Acute treatment (no vs. yes) & $3.01(1.98-4.05)$ & $<0.001$ & $3.75(2.96-4.49)$ & $<0.001$ \\
\hline Glucose (increase per unit) & $1.07(0.98-1.25)$ & 0.15 & $1.09(1.00-1.23)$ & 0.076 \\
\hline eGFR (increase per unit) & $1.02(0.93-1.43)$ & 0.13 & $1.03(1.00-1.11)$ & 0.045 \\
\hline CRP (increase per unit) & $1.03(1.00-1.09)$ & 0.015 & $1.05(1.01-1.11)$ & 0.011 \\
\hline Copeptin (Q4 vs. Q1-3) & $2.98(1.55-4.07)$ & 0.001 & $3.65(2.12-5.05)$ & $<0.001$ \\
\hline NT-pro BNP (Q4 vs. Q1-3) & $2.05(1.21-3.39)$ & 0.009 & $3.03(1.87-4.23)$ & 0.003 \\
\hline Adiponectin (increase per unit) & $1.13(1.06-1.19)$ & $<0.001$ & $1.17(1.11-1.24)$ & $<0.001$ \\
\hline
\end{tabular}

HR Hazard ratio, Cl confidence interval, BMI body mass index, NIHSS National Institutes of Health Stroke Scale, CRPC-reactive protein, NT-proBNP N-terminal fragment of precursor of B-type natriuretic peptide, TACS total anterior circulation syndrome, GFR glomerular filtration rate, CVD cardiovascular disease, MACCE major adverse cardiovascular and cerebrovascular events

a Adjusted for age, sex (female vs. male), BMI (yes vs. no), Diabetes mellitus (yes vs. no), Atrial fibrillation (yes vs. no), Previous CVD events (yes vs. no), NHISS, Stroke syndrome (TACS vs. other), Stroke subtype (Cardioembolic vs. other), Acute treatment (no vs. yes), serum levels of Glucose, CRP, eGFR, Copeptin, NT-ProBNP and Adiponectin. MACCE was defined as CVD death, nonfatal myocardial infarction, nonfatal stroke, or coronary revascularization by percutaneous coronary intervention or coronary artery bypass grafting

b Adjusted for age, BMI (yes vs. no), Previous CVD events (yes vs. no), NHISS, Stroke syndrome (TACS vs. other), Stroke subtype (Cardioembolic vs. other), Acute treatment (no vs. yes), serum levels of Glucose, CRP, eGFR, Copeptin, NT-ProBNP and Adiponectin

quartiles (adiponectin between 4.8 and $7.1 \mu \mathrm{g} / \mathrm{mL}, 7.1$ and $9.8 \mu \mathrm{g} / \mathrm{mL}$ and $>9.8 \mu \mathrm{g} / \mathrm{mL}$, respectively $)(\mathrm{P}<0.001$, log-rank test).

\section{Subgroup analysis}

HR with 95\% CI for the association of adiponectin level with MACCE and all-cause mortality stratified by subgroups (Fig. 4). As shown in the Fig. 4a, NT-pro-BNP and female enhanced the association of adiponectin with MACCE. Interestingly, the predictive value of adiponectin to predict MACCE was stronger in women patients than in those men patients (HR, 1.23; 95\%CI 1.15-1.32; vs. 1.06, 1.02-1.12; $\mathrm{P}=0.007)$. Similarly, adiponectin in those patients with higher levels of NT-ProBNP also presented better predictive value $(\mathrm{P}=0.009)$. As shown in the Fig. $4 \mathrm{~b}$, the predictive value of adiponectin to predict mortality was stronger in women patients and those patients had higher levels of NT-ProBNP and copeptin $(\mathrm{P}<0.05$, all).

\section{Discussion}

Adiponectin plays role in cerebral nervous system [29]. Adiponectin exhibits distinct associations with mortality in elders, and the adiponectin paradox as it relates to older adults had been proposed [30]. In addition, Kuwashiro et al. [31] reported that plasma levels of adiponectin were associated with neurological severity and prognosis in patients with ischemic stroke patients. This study was the first population-based study on the correlation between circulating levels of adiponectin and risk of MACCE and mortality in Chinese patients with AIS. The main findings were as following: (1) higher serum levels of adiponectin on admission were found in patients with MACCE events and nonsurvivors; (2) in multivariable models, elevated serum levels of adiponectin related to a high risk of MACCE (Q4 vs. Q1, HR=4.95, 95\% CI $3.03-7.06$ ) and mortality (Q4 vs. Q1, HR $=5.63,95 \% \mathrm{CI}$ 3.15-7.99); (3) the prognostic accuracy of the NIHSS to predict MACCE $(\mathrm{P}=0.001)$ and mortality $(\mathrm{P}<0.001)$ was improved by adiponectin; (4) the predictive value of adiponectin was more pronounced in women and patients with high levels of NT-pro-BNP $(\mathrm{P}<0.001$, all).

In fact, a paradoxical association between adiponectin and CVD events and death had been presented in previous studies. One study reported that high plasma adiponectin related to mortality during the 17 months follow-up in patients with acute stroke [32], while another study showed that higher leptin/adiponectin 
Table 4 Area under the curve for selected predictors of MACCE and mortality

\begin{tabular}{|c|c|c|c|c|}
\hline \multirow[t]{2}{*}{ Predictors } & \multicolumn{2}{|l|}{ MACCE $^{a}$} & \multicolumn{2}{|l|}{ Mortality } \\
\hline & AUC (95\%Cl) & $\mathbf{P}$ & AUC $(95 \% \mathrm{Cl})$ & $\mathbf{P}$ \\
\hline Adiponectin & $0.71(0.61-0.82)$ & - & $0.73(0.58-0.89)$ & - \\
\hline Age & $0.63(0.55-0.72)$ & $<0.001$ & $0.65(0.56-0.74)$ & $<0.001$ \\
\hline CRP & $0.65(0.57-0.75)$ & $<0.001$ & $0.68(0.59-0.77)$ & $<0.001$ \\
\hline $\mathrm{NIHSS}$ & $0.73(0.65-0.84)$ & 0.37 & $0.75(0.66-0.90)$ & 0.42 \\
\hline Copeptin & $0.73(0.66-0.85)$ & 0.17 & $0.74(0.64-0.88)$ & 0.28 \\
\hline NT-proBNP & $0.68(0.58-0.77)$ & 0.009 & $0.70(0.58-0.85)$ & 0.011 \\
\hline Model $I^{\mathrm{b}}$ & $0.76(0.68-0.88)$ & 0.001 & $0.78(0.69-0.91)$ & $<0.001$ \\
\hline Model II ${ }^{c}$ & $0.79(0.70-0.90)$ & $<0.001$ & $0.82(0.71-0.94)$ & $<0.001$ \\
\hline Model III & $0.77(0.68-0.86)$ & $<0.001$ & $0.80(0.69-0.92)$ & $<0.001$ \\
\hline Model IVe & $0.81(0.69-0.93)$ & $0.013^{f}$ & $0.84(0.72-0.96)$ & $0.005^{f}$ \\
\hline
\end{tabular}

MACCE major adverse cardiovascular and cerebrovascular events, $\mathrm{Cl}$ confidence interval, AUC Area Under Curve, NIHSS National Institutes of Health Stroke Scale, CRP C-reactive protein, NT-proBNP N-terminal fragment of precursor of B-type natriuretic peptide

a MACCE was defined as CVD death, nonfatal myocardial infarction, nonfatal stroke, or coronary revascularization by percutaneous coronary intervention or coronary artery bypass grafting

b Model I included NIHSS and Adiponectin

c Model II included NIHSS, Adiponectin, Copeptin and NT-proBNP

d Model III included NIHSS, CRP, age, Copeptin and NT-proBNP

e Model IV included model III and Adiponectin

f The P value was compared with Model III

ratio at day 1 related to better neurological outcomes in atherothrombotic AIS [33]. Wang et al. [34] reported that high adiponectin could be seen as a prognostic marker in patients with ischemic stroke. Previous research also showed that elevated adiponectin was prospectively associated with MACCE and death in patients with type 2 diabetes and acute coronary syndrome [35], type 1 diabetes [36], type 2 diabetes [37], coronary artery disease [38] and community-based population [39]. A meta-analysis showed that increased plasma levels of adiponectin related to a high risk of mortality in subjects with CVD [40], while another study reported that high plasma adiponectin levels at discharge were associated with all-cause mortality during the 11.6 years follow-up in patients with acute myocardial infarction [41]. Sasso et al. [42] showed that adiponectin played a role in progression of any stage of ischemic heart disease also in normal glucose tolerance subjects. However, Zoccali et al. [43] found that high plasma adiponectin levels related to a low risk of cardiovascular outcomes in patients with end-stage renal disease, suggesting this protein was as a protective cytokine for the cardiovascular system. In addition, the correlation between adiponectin and further cardiovascular events in type 2 diabetes had not been confirmed in another study [44]. In addition, a meta-analysis suggested that association between adiponectin levels and risk of coronary heart disease was comparatively moderate [45]. Furthermore, Laughlin et al. [46] did not support use of adiponectin for CVD risk stratification.

A meta-analysis suggested that the paradoxical association between adiponectin and mortality might be modulated by BNP [47]. Drechsler et al. [48] showed that increased adiponectin during follow-up related to a higher risk of adverse cardiovascular outcomes and death in hemodialysis patients and this association could be weakened by increased levels of NT-pro-BNP. Similarity, another study suggested that the apparently positive relationship between adiponectin and risk of CVD and mortality in asymptomatic elderly men might be achieved by elevated NT-pro-BNP [49]. Furthermore, Masuch et al. [50] found that elevated NT-proBNP might be associated with adiponectin signaling in cardiac healthy individuals. Consistent with those findings, we also found that the predictive value of adiponectin was more pronounced in patients with high levels of NT-pro-BNP $(\mathrm{P}<0.001)$.

Menzaghi et al. [51] showed that the association between adiponectin and cardiovascular mortality was observed in men but not women, suggesting a sex-specific manner [51]. A similar sexual dimorphism had been reported for the relationships between adiponectin chronic kidney disease [52] and type 2 diabetes [50]. In healthy middle-aged men, Prugger et al. [53] reported that elevated adiponectin plasma levels related to a high 10-year risk of ischemic stroke. In the largest community-based African American cohort, elevated adiponectin was associated among women not men with a higher risk of incident stroke [54]. However, our results showed that the predictive value of adiponectin was significant in both sexes and more pronounced in women.

Several drugs may affect adiponectin serum levels. In patients with type 2 diabetes, SGLT2 inhibitor treatment was associated with increased circulating adiponectin levels [55]. A meta-analysis showed a significant increase in adiponectin plasma levels after statin therapy (weighted mean difference: $+0.57 \mu \mathrm{g} / \mathrm{mL}$ ) [56], suggesting a significant association with clinical implications [57]. Furthermore, another meta-analysis found that Sitagliptin and vildagliptin increased serum adiponectin levels [58]. However, we did not obtain that information. The association between those drugs and adiponectin levels should be explored in future research.

The role of elevated adiponectin in stroke prognosis had not been elaborated. Adiponectin resistance and the confounding role of BNP had been proposed. First, several studies suggested that adiponectin resistance might lead to elevated levels of adiponectin, which would in turn predict high CVD mortality [59]. Second, BNP might directly increase adiponectin expression [60]. The correlation between adiponectin and mortality might be 


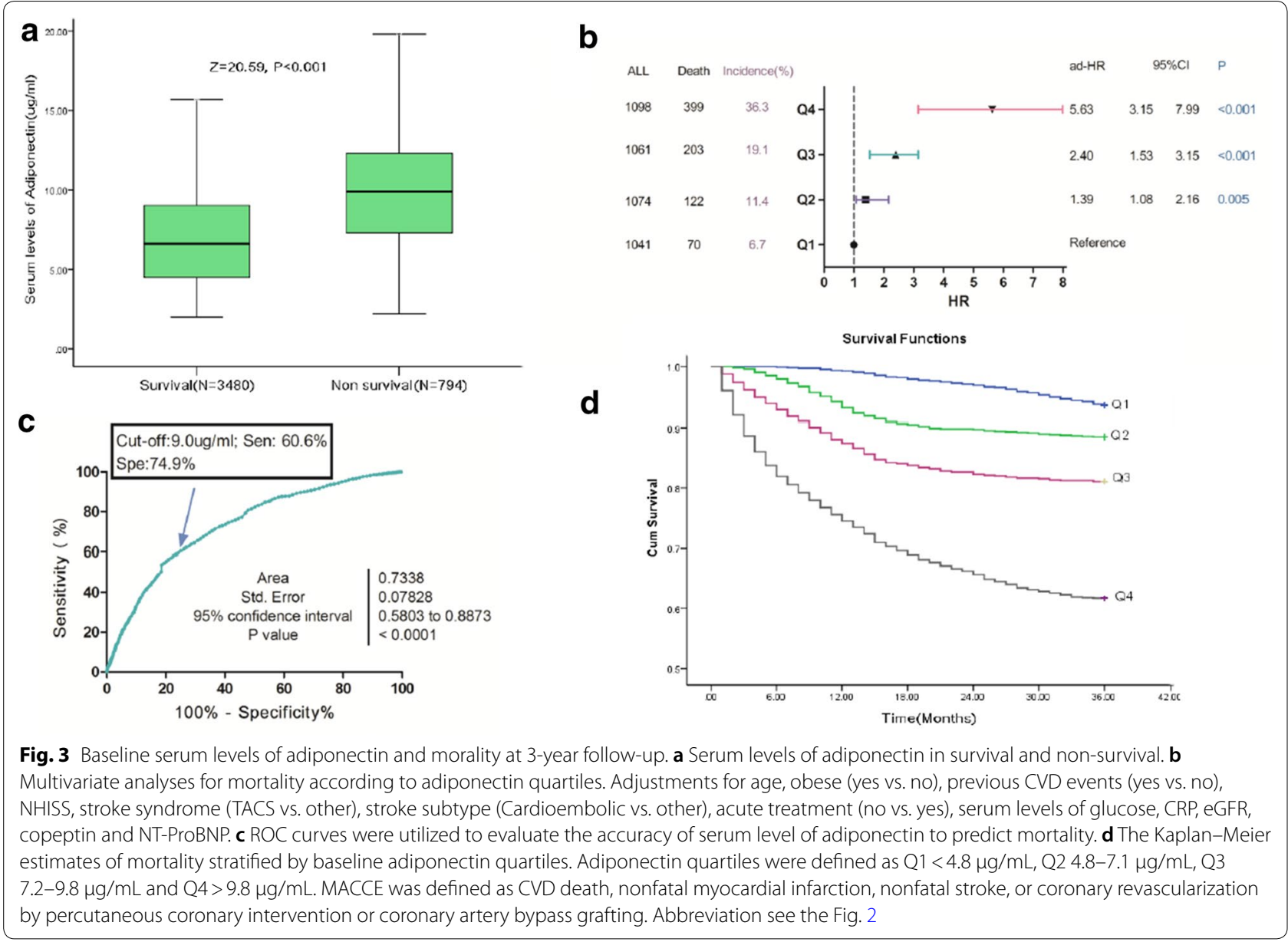

achieved through the BNP pathway [61]. However, in this study, adjusting NT-pro BNP did not change this prediction relationship. Third, reduced kidney function might act as a confounder of the association between adiponectin and mortality [8]. However, in this study, patients with renal insufficiency were excluded and eGFR were adjusted. Lastly, adiponectin could exacerbate inflammatory process in several tissues and cell types [8] and exerted proinflammatory effects by inducing chemokine production [62]. Adiponectin could increase systemic inflammation as a way to counteract proinflammatory conditions [27]. Similarly, a positive association between CRP and adiponectin had been proposed in this study.

\section{Strengths and limitations}

Our study is the first analysis of the correlation between adiponectin and risk of MACCE (mortality) in ischemic stroke patients. Furthermore, a wide range of potentially confounding risk factors, such as sex, BMI, kidney function and serum levels of BNP were collected to adjust, allowing us to observe the independent effect of adiponectin.

Some limitations also need to be considered. First, we only included Chinese. The association between adiponectin and outcomes in other populations could not be confirmed. Second, we only tested blood levels of adiponectin and no information about cerebral spinal fluid (CSF) had been obtained. In fact, a positive correlation between the plasma and CSF levels of adiponectin had been found [63]. In addition, only a single time-point blood draw after overnight fast was available. Third, we only tested total adiponectin serum levels. In fact, three isoforms of adiponectin had been reported (high, middle, and low molecular weight) and high molecular weight adiponectin had the most biologically active [64]. Fourth, adiponectin exerts its effects through the activation of 3 receptors [5]. However, we did not test the activity of the adiponectin receptors. Furthermore, secretion of adipokines, including omentin-1 [65], retinol-binding protein 4 (RBP4) [66], fatty acid-binding protein 4 (FABP4) [67] 
a Al

\section{$A G E<60$}

$A G E \gtrless 60$

MALE

FEIMALE

NO DIATETES

DIATETES

$B M \mid<27$

$\mathrm{BM} \mid \geqslant 27$

eGFR<60

eGFR $\geqslant 60$

CRP $<5$

$C R P \ngtr 5$

NT-ProBNP<median NT-ProBNP $\gg$ median

Copeptin<median

Copeptin $\gtrsim$ median

b ALL

$A G E<60$

AGE $\geqslant 60$

MALE

FEIMALE

NO DUATETES

DIATETES

$B M \mid<27$

$B M \mid \geqslant 27$

eGFR<60

eGFR $\geqslant 60$

CRP $<5$

CRP $\geqslant 5$

NT-ProBNP<median

$N T-P$ roBNP $\geqslant$ median

Copeptin $<$ median

Copeptin $\geqslant$ median
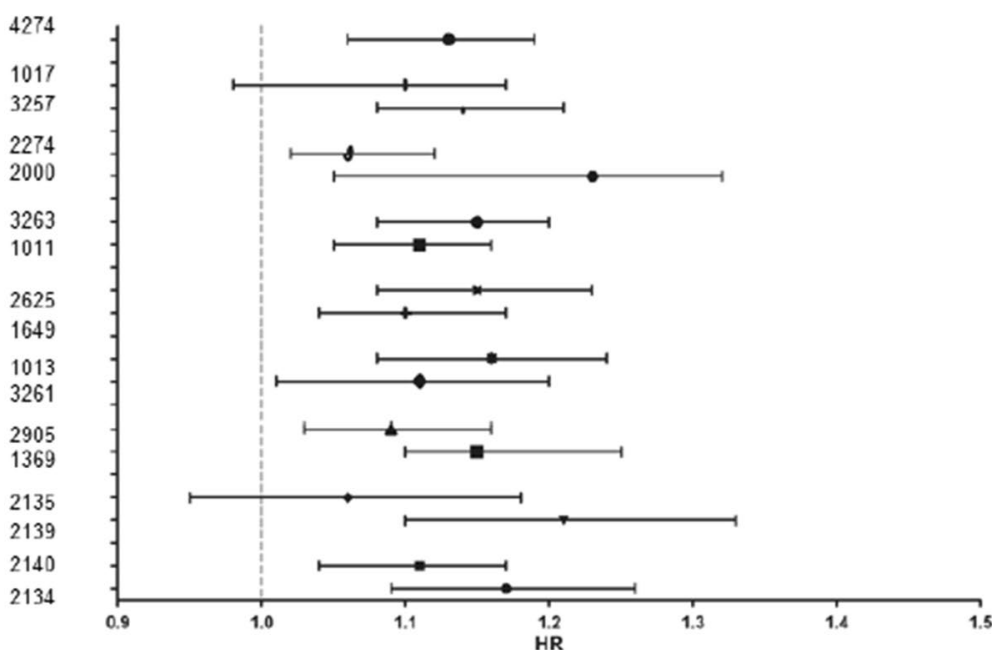

P-interaction

$\mathrm{P}=0.25$

$P=0.007$

$P=0.53$

$P=0.16$

$P=0.21$

$P=0.27$

$\mathrm{P}=0.009$

$\mathrm{P}=0.095$

P-interaction

$P=0.18$

$P=0.006$

$P=0.44$

$P=0.12$

$P=0.28$

$P=0.16$

$P=0.003$

$P=0.031$

Fig. 4 Hazard ratio with $95 \%$ CI for the association of adiponectin level with MACCE and all-cause mortality stratified by subgroups. a Hazard ratio with $95 \%$ confidence intervals for the association of adiponectin level with MACCE stratified by subgroups. b Hazard ratio with $95 \%$ confidence intervals for the association of adiponectin level with all-cause mortality stratified by subgroups. Abbreviation see the Fig. 2

was altered in adipose tissue dysfunction and might play role in the prognosis of stroke. A previous study also found that omentin plasma levels were inversely associated with intima-media thickness in diabetes patients with increased adiponectin levels [68]. However, in this study, we did not test those biomarkers, thus, the association between adiponectin, others adipokines and stoke outcomes could not be obtained. Lastly, an observational study could not draw any causal relationship. Moreno et al. [69] suggested that the paradoxical association between adiponectin and mortality was a cause-effect relationship.

\section{Conclusions}

Elevated serum levels of adiponectin were associated with a higher risk of MACCE and mortality independent of traditional risk factors in ischemic stroke patients, indicating adiponectin play a role in progression of ischemic stroke.

\section{Abbreviations}

HF: Heart failure; CVD: Cardiovascular disease; MACCE: Major adverse cardiovascular and cerebrovascular events; AIS: Acute ischemic stroke; NIHSS: National Institutes of Health Stroke Scale; DWI: Diffusion-weighted imaging; eGFR: Estimated glomerular filtration rate; CKD-EPI: Chronic Kidney Disease Epidemiology Collaboration; CRP: C-reactive protein; NT-proBNP: N-terminal of the prohormone B-type natriuretic peptide; IQR: Interquartile ranges; HR: 
Hazard ratio; Cl: Confidence interval; ROC: Receiver operating characteristic; AUC: Area under the curve; NRI: Net reclassification improvement.

\section{Acknowledgements}

All authors have contributed significantly and agreed with the content of the manuscript. We are grateful to all the people who participated in our study. We also thank Andrea Baird, MD, from Edanz Editing China (www.liwenbianj i.cn/ac), for editing the English text of a draft of this manuscript.

\section{Authors' contributions}

ZXW had full access to all of the data in the study and takes responsibility for the integrity of the data and the accuracy of the data analysis. TWJ, QHC, LYK, ZJZ, ZXW and LQ contributed to the study concept and design. TWJ, QHC and LLY contributed to the acquisition of the data. Tu WJ and Zeng XW carried out the analysis and interpretation of the data. TWJ, QHC, LYK and LQ contributed in the drafting of the manuscript. ZXW and LQ are responsible for the critical revision of the manuscript for important intellectual content. TWJ, QHC and LYK are responsible for the administrative, technical, or material support. ZXW and LQ obtained the funding and supervised. All authors read and approved the final manuscript.

\section{Funding}

This study was supported by grants from National Natural Science Foundation of China (No. 81671175), Technology Ministry of science and technology support program (No. 2015BAl06B05), "13th Five-Year Plan" National Science and Technology Supporting Plan (No. 2015BAl12B04), Beijing Science and Technology Supporting Plan (No. D16110000381605) and the Beijing Municipal Administration of Hospitals' Mission Plan (No. SML20150501), China Postdoctoral Science Foundation funded project (No. 2019M660921 and 2020T130118), Natural Science Foundation of Tianjin (No.19JCYBJC26600), Science Foundation for Post Doctorate Research of the Beijing (No.2017ZZ-123 and 2020-ZZ-005). The funding plays no role in the design and concept of the study; the collection, management, analysis, and interpretation of the data; or the preparation, review, or approval of the manuscript.

\section{Availability of data and materials}

Please contact the correspondence author for the data request (Dr. Zeng).

\section{Ethics approval and consent to participate}

The design of study was reviews and approves by investigational review board of the Affiliated Hospital of Weifang Medical College according to the principles of the Declaration of Helsinki (trial registration no. ChiCTRROC-17013501). Informed consents were obtained from patients or their relatives (patients unable to communicate) prior to their inclusion in this study.

\section{Consent for publication}

None.

\section{Competing interests}

None.

\section{Author details}

1 Department of Neurosurgery, Beijing Tiantan Hospital, Capital Medical University, No. 119, South Four Ring West Road, Beijing 100070, People's Republic of China. ${ }^{2}$ Department of Neurosurgery, Qilu Hospital of Shandong University, No. 107 Wenhua West Road, Jinan 250012, Shandong, People's Republic of China. ${ }^{3}$ Institute of Radiation Medicine, China Academy of Medical Science \& Peking Union Medical College, Tianjin, China. ${ }^{4}$ China National Clinical Research Center for Neurological Diseases, Beijing, China. ${ }^{5}$ Center of Stroke, Beijing Institute for Brain Disorders, Beijing, China. ${ }^{6}$ Beijing Key Laboratory of Translational Medicine for Cerebrovascular Disease, Beijing, China.

Received: 12 March 2020 Accepted: 25 July 2020

Published online: 08 August 2020

\section{References}

1. Tu WJ, Qiu HC, Zhang Y, et al. Lower serum retinoic acid level for prediction of higher risk of mortality in ischemic stroke. Neurology. 2019;92(15):e1678-87.
2. The GBD 2016 Lifetime Risk of Stroke Collaborators. Global, regional, and country-specific lifetime risks of stroke, 1990 and 2016. N Engl J Med. 2018;379:2429-37.

3. Li S, Shin HJ, Ding EL, et al. Adiponectin levels and risk of type 2 diabetes: a systematic review and meta-analysis. JAMA. 2009;302(2):179-88.

4. Pessin JE, Kwon H. Adipokines mediate inflammation and insulin resistance. Front Endocrinol. 2013;4:71.

5. Lopez-Jaramillo P. The role of adiponectin in cardiometabolic diseases: effects of nutritional interventions. J Nutri. 2016;146(2):422S-6S.

6. Sun L, Liu X. Functions of adiponectin signaling in regulating neural plasticity and its application as the therapeutic target to neurological and psychiatric diseases. Rev Neurosci. 2019;30(5):485-95.

7. Bloemer J, Pinky PD, Govindarajulu M, et al. Role of adiponectin in central nervous system disorders. Neural Plasticity. 2018. https://doi. org/10.1155/2018/4593530.

8. Menzaghi C, Trischitta V. The adiponectin paradox for all-cause and cardiovascular mortality. Diabetes. 2018;67(1):12-22.

9. Ohashi K, Parker JL, Ouchi N, et al. Adiponectin promotes macrophage polarization toward an anti-inflammatory phenotype. J Biol Chem. 2010;285:6153-60.

10. $\mathrm{Hu}$ J, Li J, Liang L, et al. Abstract P049: circulating adiponectin levels and risk of type 2 diabetes, cardiovascular disease, and all-cause mortality in US women. Circulation. 2019;139:AP049.

11. Menon V, Li L, Wang X, Greene T, Balakrishnan V, Madero M, Pereira AA, Beck GJ, Kusek JW, Collins AJ, Levey AS, Sarnak MJ. Adiponectin and mortality in patients with chronic kidney disease. J Am Soc Nephrol. 2006;17:2599-606.

12. Kistorp C, Faber J, Galatius S, Gustafsson F, Frystyk J, Flyvbjerg A, Hildebrandt P. Plasma adiponectin, body mass index, and mortality in patients with chronic heart failure. Circulation. 2005;112:1756-62.

13. Cavusoglu E, Ruwende C, Chopra V, Yanamadala S, Eng C, Clark LT, et al. Adiponectin is an independent predictor of all-cause mortality, cardiac mortality, and myocardial infarction in patients presenting with chest pain. Eur Heart J. 2006;27:2300-9.

14. Poehls J, Wassel CL, Harris TB, Havel PJ, Swarbrick MM, Cummings SR, et al. Association of adiponectin with mortality in older adults: the health, aging, and body composition study. Diabetologia. 2009;52:591-5.

15. Teoh H, Strauss MH, Szmitko PE, Verma S. Adiponectin and myocardial infarction: a paradox or a paradigm? Eur Heart J. 2006;27:2266-8.

16. Hao G, Li W, Guo R, et al. Serum total adiponectin level and the risk of cardiovascular disease in general population: a meta-analysis of 17 prospective studies. Atherosclerosis. 2013;228(1):29-35.

17. Yang J, Du G, Wang J, et al. Reduced serum adiponectin level and risk of poststroke depression in patients with ischemic stroke. J Stroke Cerebrovascular Dis. 2019;28(2):305-10.

18. Ithan N, Susam S, Canpolat O, et al. The emerging role of leptin, Adiponectin and Visfatin in Ischemic/Hemorrhagic stroke. Br J Neurosurg. 2019;33(5):504-7.

19. Kanhai DA, Kranendonk ME, Uiterwaal C, et al. Adiponectin and incident coronary heart disease and stroke A systematic review and meta-analysis of prospective studies. Obesity Rev. 2013;14(7):555-67.

20. Arregui M, Buijsse B, Fritsche A, et al. Adiponectin and risk of stroke: prospective study and meta-analysis. Stroke. 2014;45(1):10-7.

21. Efstathiou SP, Tsioulos DI, Tsiakou AG, et al. Plasma adiponectin levels and five-year survival after first-ever ischemic stroke. Stroke. 2005;36(9):1915-9.

22. Sook Lee E, Park S, Kim E, et al. Association between adiponectin levels and coronary heart disease and mortality: a systematic review and metaanalysis. Int J Epidemiol. 2013;42(4):1029-39.

23. Liberale L, Carbone F, Bertolotto M, et al. Serum adiponectin levels predict acute coronary syndrome (ACS) in patients with severe carotid stenosis. Vascul Pharmacol. 2018;102:37-43.

24. Zeng X, Deng A, Ding Y, et al. Copeptin and NT-proBNP as prognostic markers for recurrent ischemic cerebrovascular events in ischemic stroke patients. J Am Coll Cardiol. 2016;68(24):2710-1.

25. Brott T, Adams HP Jr, Olinger CP, Marler JR, Barsan WG, Biller J, Spilker J, Holleran R, Eberle R, Hertzberg V. Measurements of acute cerebral infarction: a clinical examination scale. Stroke. 1989;20:864-70.

26. Tu WJ, Ma GZ, Ni Y, et al. Copeptin and NT-proBNP for prediction of all-cause and cardiovascular death in ischemic stroke. Neurology. 2017;88(20):1899-905. 
27. Witberg G, Ayers CR, Turer AT, et al. Relation of adiponectin to all-cause mortality, cardiovascular mortality, and major adverse cardiovascular events (from the Dallas Heart Study). Am J Cardiol. 2016;117(4):574-9.

28. Levey AS, Stevens LA, Schmid CH, et al. A new equation to estimate glomerular filtration rate. Ann Intern Med. 2009;150:604-12.

29. Li X, Guo H, Zhao L, et al. Adiponectin attenuates NADPH oxidase-mediated. Biochimica et Biophysica Acta. 2017;1863(12):3265-76.

30. Kizer JR, Benkeser D, Arnold AM, et al. Associations of total and highmolecular-weight adiponectin with all-cause and cardiovascular mortality in older persons: the Cardiovascular Health Study. Circulation. 2012;126(25):2951-61.

31. Kuwashiro T, Ago T, Kamouchi M, et al. Significance of plasma adiponectin for diagnosis, neurological severity and functional outcome in ischemic stroke-Research for Biomarkers in Ischemic Stroke (REBIOS). Metabolism. 2014;63(9):1093-103.

32. Nagasawa H, Yokota C, Toyoda K, et al. High level of plasma adiponectin in acute stroke patients is associated with stroke mortality. J Neurol Sci. 2011;304(1-2):102-6.

33. Carbone F, Burger F, Roversi G, Tamborino C, Casetta I, Seraceni S, Mach F. Leptin/adiponectin ratio predicts poststroke neurological outcome. Eur J Clin Invest. 2015;45(11):1184-91.

34. Wang Z, Li B, Wang Y, Maimaitili A, Qin H, Dangmurenjiafu G, Wang S. The association between serum adiponectin and 3-month outcome after ischemic stroke. Cardiovascu Diabetol. 2019;18(1):105.

35. Schrieks IC, Nozza A, Stähli BE, et al. Adiponectin, free fatty acids, and cardiovascular outcomes in patients with type 2 diabetes and acute coronary syndrome. Diab Care. 2018;41(8):1792-800.

36. Forsblom C, Thomas MC, Moran J, et al. Serum adiponectin concentration is a positive predictor of all-cause and cardiovascular mortality in type 1 diabetes. J Intern Med. 2011;270(4):346-55.

37. Singer JR, Palmas W, Teresi J, et al. Adiponectin and all-cause mortality in elderly people with type 2 diabetes. Diab Care. 2012;35(9):1858-63.

38. Hascoet S, Elbaz M, Bongard V, et al. Adiponectin and long-term mortality in coronary artery disease participants and controls. Arterioscler Thromb Vasc Biol. 2013;33(1):e19-29.

39. Lindberg S, Mogelvang R, Pedersen SH, et al. Relation of serum adiponectin levels to number of traditional atherosclerotic risk factors and all-cause mortality and major adverse cardiovascular events (from the Copenhagen City Heart Study). Am J Cardiol. 2013;111(8):1139-45.

40. Wu ZJ, Cheng YJ, Gu WJ, et al. Adiponectin is associated with increased mortality in patients with already established cardiovascular disease: a systematic review and meta-analysis. Metabolism. 2014;63(9):1157-66.

41. Ritsinger V, Brismar K, Malmberg K, et al. Elevated levels of adipokines predict outcome after acute myocardial infarction: a long-term follow-up of the glucose tolerance in patients with acute myocardial infarction cohort. Diab Vascu Dis Res. 2017;14(2):77-87.

42. Sasso FC, Pafundi PC, Marfella R, Calabrò P, Piscione F, Furbatto F, Salvatore T. Adiponectin and insulin resistance are related to restenosis and overall new $\mathrm{PCl}$ in subjects with normal glucose tolerance: the prospective AIRE Study. Cardiovascu Diabetol. 2019;18(1):24.

43. Zoccali C, Mallamaci F, Tripepi G, et al. Adiponectin, metabolic risk factors, and cardiovascular events among patients with end-stage renal disease. J Am Soc Nephrol. 2002;13(1):134-41.

44. Jeon JY, Ha KH, Han SJ, et al. Blood adiponectin levels are not associated with risk of cardiovascular events in patients with type 2 diabetes. Diab Vascular Dis Res. 2018;15(6):571-5.

45. Sattar N, Wannamethee G, Sarwar N, et al. Adiponectin and coronary heart disease: a prospective study and meta-analysis. Circulation. 2006;114:623-9.

46. Laughlin GA, Barrett-Connor E, May S, Langenberg C. Association of adiponectin with coronary heart disease and mortality: the Rancho Bernardo study. Am J Epidemiol. 2007;165:164-74.

47. Scarale MG, Fontana A, Trischitta V, et al. Circulating adiponectin levels are paradoxically associated with mortality rate: a systematic review and meta-analysis. J Clin Endocrinol Metab. 2018;104(5):1357-68.

48. Drechsler C, Krane V, Winkler K, et al. Changes in adiponectin and the risk of sudden death, stroke, myocardial infarction, and mortality in hemodialysis patients. Kidney Int. 2009;76(5):567-75.

49. Wannamethee SG, Welsh P, Whincup PH, et al. High adiponectin and increased risk of cardiovascular disease and mortality in asymptomatic older men: does NT-proBNP help to explain this association? Eur J Cardiovascu Prevent Rehab. 2011;18(1):65-71.

50. Masuch A, Pietzner M, Bahls M, et al. Metabolomic profiling implicates adiponectin as mediator of a favorable lipoprotein profile associated with NT-proBNP. Cardiovascu Diabetol. 2018;17(1):120.

51. Menzaghi C, Xu M, Salvemini L, et al. Circulating adiponectin and cardiovascular mortality in patients with type 2 diabetes mellitus: evidence of sexual dimorphism. Cardiovasc Diabetol. 2014;13:130.

52. Kollerits B, Fliser D, Heid IM, Ritz E, Kronenberg F, MMKD Study Group. Gender-specific association of adiponectin as a predictor of progression of chronic kidney disease: the Mild to Moderate Kidney Disease Study. Kidney Int. 2007;71:1279-86.

53. Prugger C, Luc G, Haas B, et al. Adipocytokines and the risk of ischemic stroke: the PRIME Study. Ann Neurol. 2012;71(4):478-86.

54. Bidulescu A, Liu J, Chen Z, et al. Associations of adiponectin and leptin with incident coronary heart disease and ischemic stroke in African Americans: the Jackson Heart Study. Front Public Health. 2013;1:16.

55. Wu P, Wen W, Li J, et al. Systematic review and meta-analysis of randomized controlled trials on the effect of SGLT2 inhibitor on blood leptin and adiponectin level in patients with type 2 diabetes. Horm Metab Res. 2019;51(08):487-94.

56. Chruściel P, Sahebkar A, Rembek-Wieliczko M, et al. Impact of statin therapy on plasma adiponectin concentrations: a systematic review and meta-analysis of 43 randomized controlled trial arms. Atherosclerosis. 2016;253:194-208.

57. Katsiki N, Mantzoros CS. Statins in relation to adiponectin: a significant association with clinical implications. Atherosclerosis. 2016;253:270-2.

58. Liu X, Men P, Wang Y, et al. Impact of dipeptidyl peptidase-4 inhibitors on serum adiponectin: a meta-analysis. Lipids Health Dis. 2016;15(1):1-9.

59. Khan RS, Kato TS, Chokshi A, et al. Adipose tissue inflammation and adiponectin resistance in patients with advanced heart failure: correction after ventricular assist device implantation. Circ Heart Fail. 2012;5:340-8.

60. Tsukamoto O, Fujita M, Kato M, Yamazaki S, Asano Y, Ogai A, Okazaki H, Asai M, Nagamachi Y, Maeda N, Shintani Y, Minamino T, Asakura M, Kishimoto I, Funahashi T, Tomoike H, Kitakaze M. Natriuretic peptides enhance the production of adiponectin in human adipocytes and in patients with chronic heart failure. J Am Coll Cardiol. 2009;53:2070-7.

61. Wang TJ, Larson MG, Levy D, et al. Plasma natriuretic peptide levels and the risk of cardiovascular events and death. N Engl J Med. 2004;350:655-63.

62. Ogunwobi $\bigcirc 0$, Beales IL. Adiponectin stimulates proliferation and cytokine secretion in colonic epithelial cells. Regul Pept. 2006;134:105-13.

63. Une K, Takei YA, Tomita N, Asamura T, Ohrui T, Furukawa K, Arai H. Adiponectin in plasma and cerebrospinal fluid in $\mathrm{MCl}$ and Alzheimer's disease. Eur J Neurol. 2011;18:1006-9.

64. Gairolla J, Kler R, Modi M, et al. Leptin and adiponectin: pathophysiological role and possible therapeutic target of inflammation in ischemic stroke. Rev Neurosci. 2017;28(3):295-306.

65. Wu DM, Wang S, Wen X, et al. Impact of serum omentin-1 levels on functional prognosis in nondiabetic patients with ischemic stroke. Am J Transl Res. 2019;11(3):1854-63.

66. Zhu Y, Zhang J, Liu L, et al. Evaluation of serum retinol-binding protein-4 levels as a biomarker of poor short-term prognosis in ischemic stroke. Biosci Rep. 2018. https://doi.org/10.1042/BSR20180786.

67. Tu WJ, Zeng XW, Deng A, et al. Circulating FABP4 (fatty acid-binding protein 4) is a novel prognostic biomarker in patients with acute ischemic stroke. Stroke. 2017;48(6):1531-8.

68. Nishimura M, Morioka T, Hayashi M, Kakutani Y, Yamazaki Y, Kurajoh M, Inaba M. Plasma omentin levels are inversely associated with atherosclerosis in type 2 diabetes patients with increased plasma adiponectin levels: a cross-sectional study. Cardiovascu Diabetol. 2019;18(1):167.

69. Moreno LO, Copetti M, Fontana A, et al. Evidence of a causal relationship between high serum adiponectin levels and increased cardiovascular mortality rate in patients with type 2 diabetes. Cardiovascu Diabetol. 2016;15(1):17.

\section{Publisher's Note}

Springer Nature remains neutral with regard to jurisdictional claims in published maps and institutional affiliations. 